\title{
Design of a High-Efficient Grid-Connected Three-Phase Three-Level T-Type PV Power System
}

\author{
Jinsoo Kim and Oh Yang \\ Electronic Engineering of Cheong-ju University \\ jinsoa@gmail.com,ohyang@cju.ac.kr
}

\begin{abstract}
This paper intends to design a high-efficient grid connected three-phase three-level T-type photovoltaic inverter system which is operated with conjunction with grid. Different from the two-level topology mainly used previous, switch elements are increased by 6 pieces, it has the advantages such as the efficiency of the inverter, less stress in the switching elements, and less harmonic component in the output current. This paper will suggest the boost convert always supplying constant DC voltage for a three-phase three-level T-type photovoltaic inverter, and also presents the stability and excellence of the 3 level boost converter through experiments. Also, it offers the stable and high-efficient MPPT algorism and through solar irradiation change experiment and MPPT efficiency assessment, the excellence and efficacy of three-level T-type inverter was verified from experiments.
\end{abstract}

Keywords: Three-Phase Grid-connected PV Inverter, Photovoltaic, MPPT, PLL, ThreeLevel Boost Converter, T-type photovoltaic inverter

\section{Introduction}

Recently, due to the environmental pollution and depletion of fossil fuels, alternative energy studies have been on the progress, and in particular, the photovoltaic research is constantly being conducted. As electricity generated from solar power system is operating the energy more efficiently in connection with electricity grid, and from the user's standpoint, it is more stable, the electricity grid-connected technology produced from the solar power system is becoming a lot of interest [1].

Electricity generated from photovoltaic system is changeable in its operating characteristic and maximum output depending upon the amount of solar radiation, operating voltage and operating temperature etc. Accordingly, it is necessary to draw a lot of energy from the solar cell and increase the efficacy. MPPT (Maximum Power Point Tracking) controlling technique (which controls the operating point of solar cell in order to always operate at the maximum output in the consideration of the environmental sectors such as temperature or amount of solar radiations as well as the photovoltaic output changeable depending upon the operating status) and DC to DC converter controlling technique which is to provide the stable DC power from inverter are essential [2].

For PCS of photovoltaic system, many topologies and new techniques are now proposed in various ways. The existing three-phase two-level photovoltaic inverter can be implemented easily by using the simple composition and already proved controlling and PWM techniques. However, 2-level inverter has disadvantages such as high harmonic content in the output voltage, efficient limitation, and a lot of stress on the switching element (IGBT). Meanwhile, the 3-level T-Type topology has the advantages such as the inverter's efficacy of the existing 2-level inverter, the high harmonic content, less stress of the switching element, however, the disadvantage that its circuit is more complex than that of the existing 2 level inverter [3]. 
This paper intends to design the boost converter always supplying constant DC voltage to inverter for a 3-phase 3-levels T-Type photovoltaic inverter and, through experiments, presents the stability of a 3 levels boost converter. And it also intend to verify, through solar irradiation change experiment and MPPT efficacy assessment on MPPT, the excellence of three level T-type inverter and the proposed algorism.

\section{Grid Connected Three-Phase Three-level T-Type Photovoltaic Inverter}

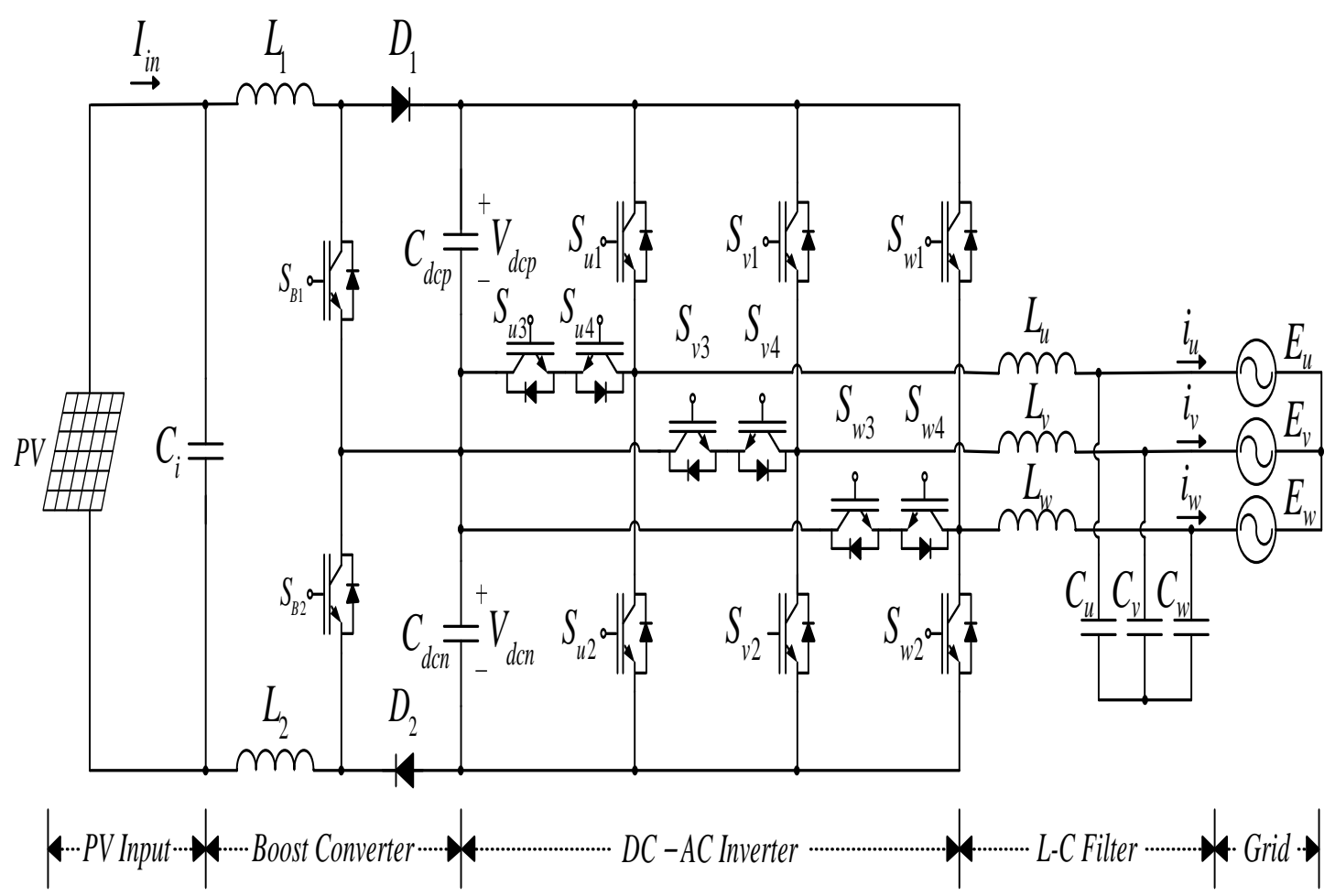

Figure 1. Circuit Diagram of Three-phase Three-level T-Type PV Inverter

For PCS of photovoltaic system, many topologies and new techniques are now proposed in various ways. Low-frequency transformer method, high-frequency link system, nontransformer method are mainly used, and each topology has advantages and disadvantages. However, this paper implements the system using the topology of non-transformer method which as the advantageous characteristics of high efficacy, small size, and light weight, not using the low frequency transformer method $[4,5]$.

Grid connected photovoltaic generation system is composed of the boost converter which maintains a constant voltage regardless of the solar cell module and input voltage supplying DC power source to photovoltaic inverter, and the inverter which converts to the grid AC .

Figure 1 shows the three-level T-Type topology of three-phase grid-connected photovoltaic inverter which is proposed in this paper. By using 12 pieces of IGBT, it implements a DC-AC inverter, and by using a reactor $\mathrm{L}$ and a $\mathrm{C}$ filter disconnected with $\mathrm{Y}$ at the inverter output part, reduces the ripple of output and harmonic components.

The control techniques for the grid-connected photovoltaic inverter requires PPL control technique to supply power to the grid, and MPPT control technique to maximize the power generation of solar cell modules, and the output current control technique to output the outputting current to the grid. 


\subsection{Three-Level Boost Converter}

Photovoltaic should constantly maintain the dc link voltage in order to convert the DC power of solar cells to the AC power of the inverter. However, a power-voltage curves, a current-voltage curves of the solar cells tends to be nonlinearly changed according to the external environment such as amount of solar radiation, temperature etc. So, to supply the constant power to the inverter in accordance with these nonlinear characteristics, the boost converter is inevitable [6].

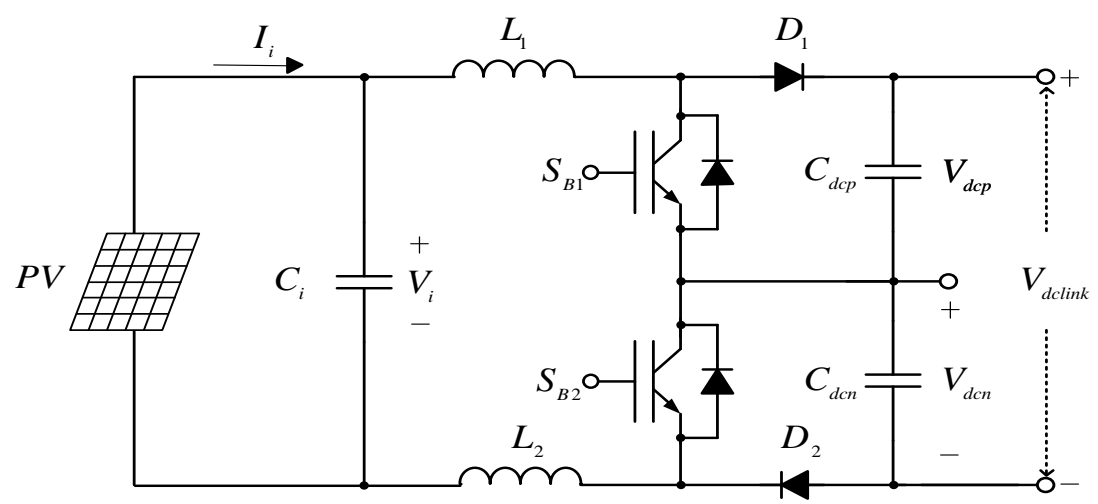

Figure 2. Circuit Diagram of Three Level Boost Converter

Figure 2 shows the three-level boost converter circuit implemented in this paper. In comparison with the conventional two level boost converter, three level boost converter has the superiority in terms of that voltage gain is doubled but the voltage across the switching element and diode halves. Also, through the control of midpoint, it also has the advantage to maintain the voltages of $V_{d c p}$ and $V_{d c n}$ equivalently so as to implement the multi-level inverter.

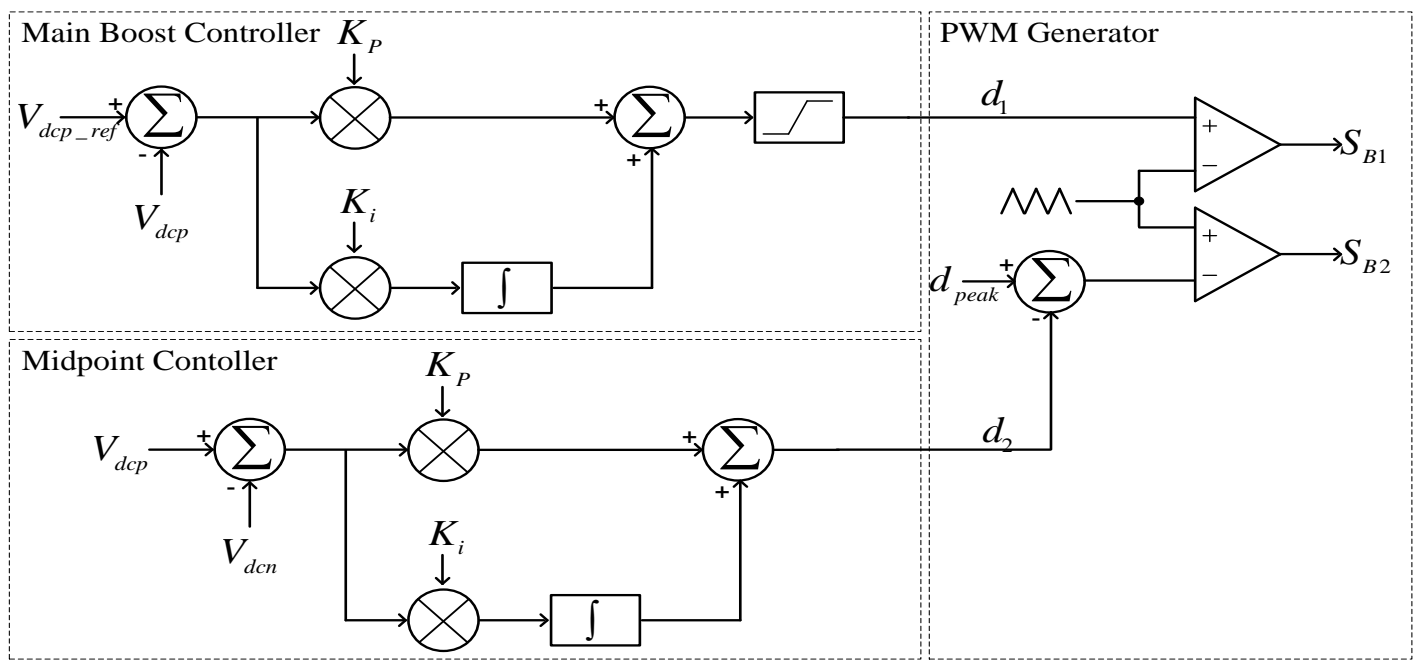

Figure 3. Block Diagram of Three Level Boost Converter

Figure 3 is the structure of boost converter to implement the optimal MPPT algorithm. Boost converter has two controllers and one PWM Generator. The controller controls the output power by using a PI controller which is widely used in automation systems. Usually 
the voltage unbalances between $V_{d c p}$ and $V_{d c n}$ can occur. To reduce this voltage unbalance, the difference between two voltages is to be controlled to 0 through PI controller. Finally, the PWM Generator generates PWM by using $d_{1}$ and $d_{2}$ which come out of the controller [7].

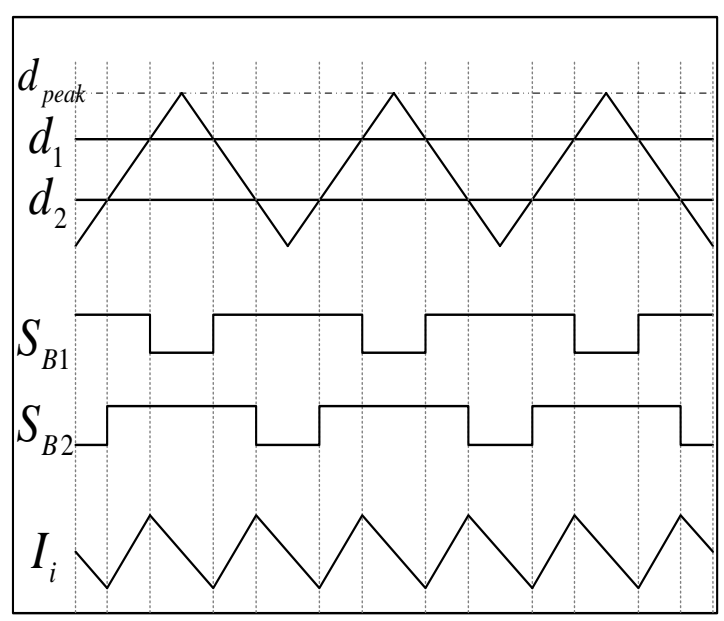

(a) $0.5 \leq d_{1} \leq 1$ or $V_{i} \geq \frac{V_{d c l i n k}}{2}$

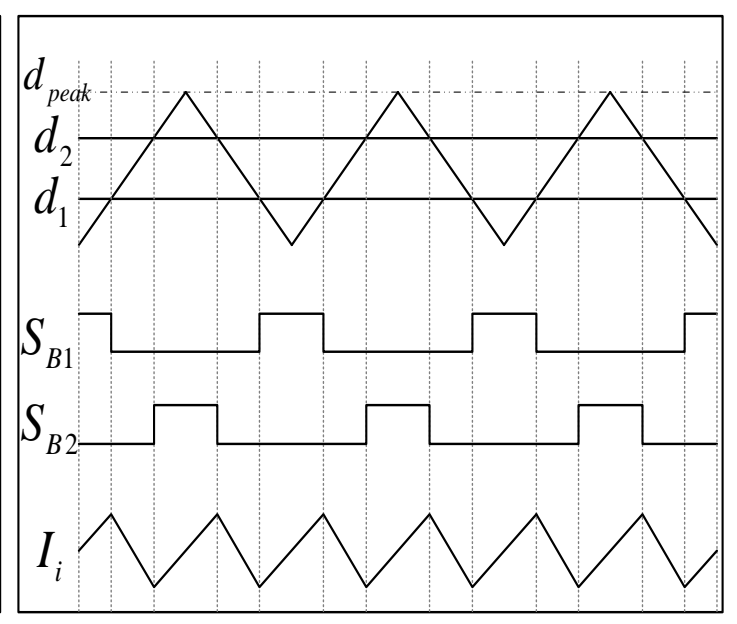

(b) $0 \leq d_{1}<0.5$ or $V_{i}<\frac{V_{d c l i n k}}{2}$

Figure 4. Key Wave Form of Three Level Boost Converter

Figure 4 shows the important waveforms concerning the proposed three level boost converter waveforms. In Figure 4, the waveform of (a) is the waveform showing that $d_{1}$ is located over $50 \%$ when $V_{i}$ is greater or equal than $V_{\text {dclink }} / 2$, and (b) is the waveform showing that $d_{1}$ is located less than $50 \%$, when $V_{i}$ is smaller than $V_{d c l i n k} / 2$.

\subsection{MPPT(Maximum Power Point Tracking)}

Grid connected photovoltaic inverter should always generate the maximum power from the solar cells with the non-linear current characteristics and requires the stable control. If it doesn't follow the maximum power or unstable, the output power from the inverter is controlled unstably and the power quality becomes degraded. The MPPT algorithm proposed in this paper stably follows the maximum power point and, in case of the rapid fluctuations of solar radiation, it also follows the maximum power point [8].

MPPT method is differentiated into two methods. One is the method to change Duty Cycle of the Boost Converter and the other is the method to change the current of inverter maintaining DC link reference voltage by the Boost converter with PI controller. The MPPT algorithm to be proposed by this paper is designed in the method to change the pulse width of the Boost converter, and the flow chart of the algorithm is shown in Figure 5.

Figure 5 shows the flow chart of MPPT algorithm proposed in this paper. It is the method to follow the maximum power point of the solar cell arrays by comparing the present power and the past power as well as increasing or decreasing the output voltage of the solar cell array. When solar cell voltage $\left(V_{\text {solar }}\right)$ is smaller than the minimum DC link voltage $\left(V_{\text {Boost_min }}\right)$, the DC link reference voltage ( $V_{\text {Boost_ } r \text { ef }}$ ) is to fix as the DC link minimum voltage and either increasing or decreasing the pulse width of booster-type converter, follow the maximum 
power point. When the solar cell voltage is greater than the DC link minimum voltage, DC link reference voltage $V_{\text {Boost_ref }}$ is to set as the DC link voltage $V_{D C L I N K}$, and either increasing or decreasing the DC link reference voltage, follow the maximum power point. Accordingly, it is possible to follow without the intervention of open-circuit voltage of the solar cell.

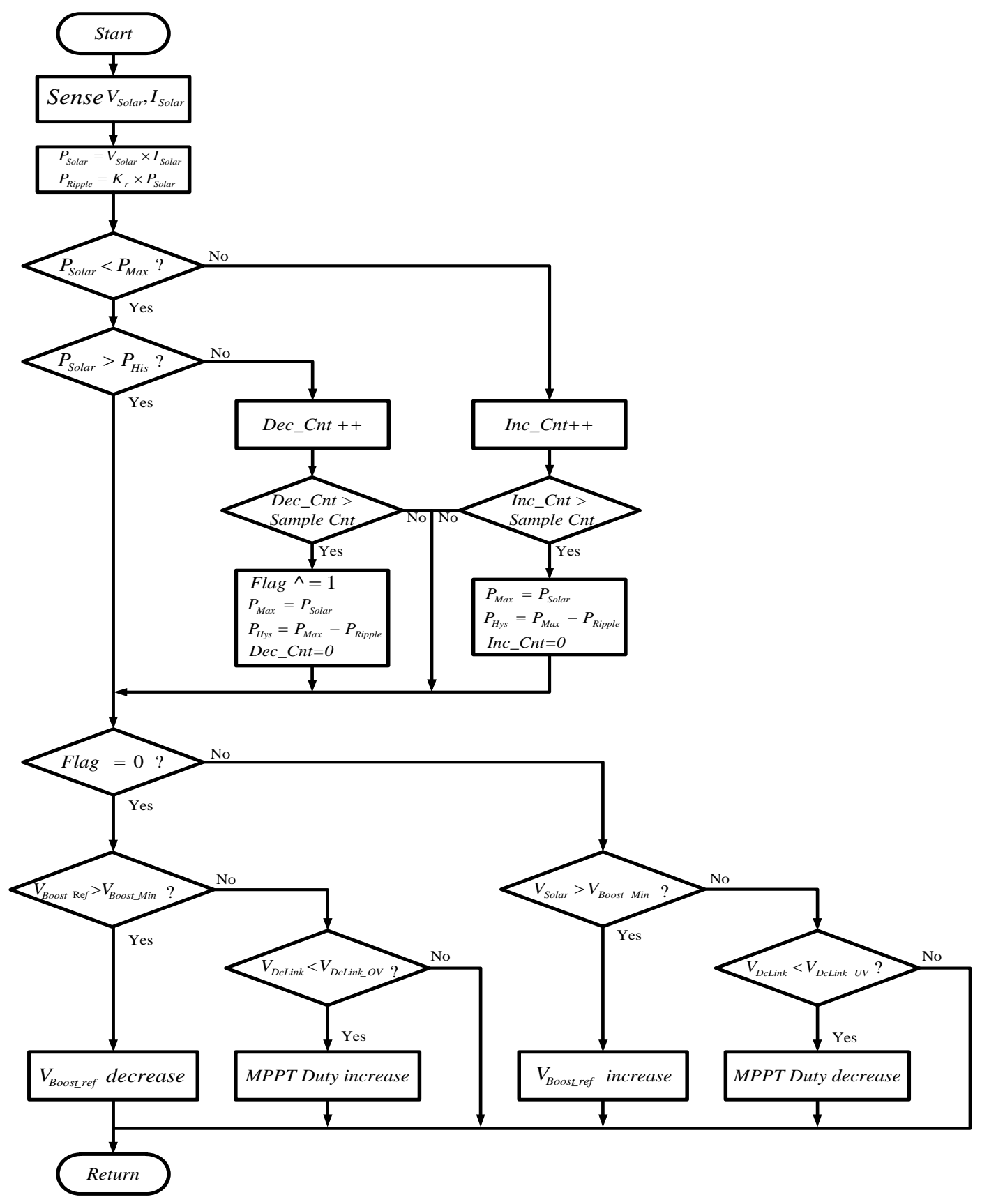

Figure 5. Flowchart of Proposed MPPT Algorithm 


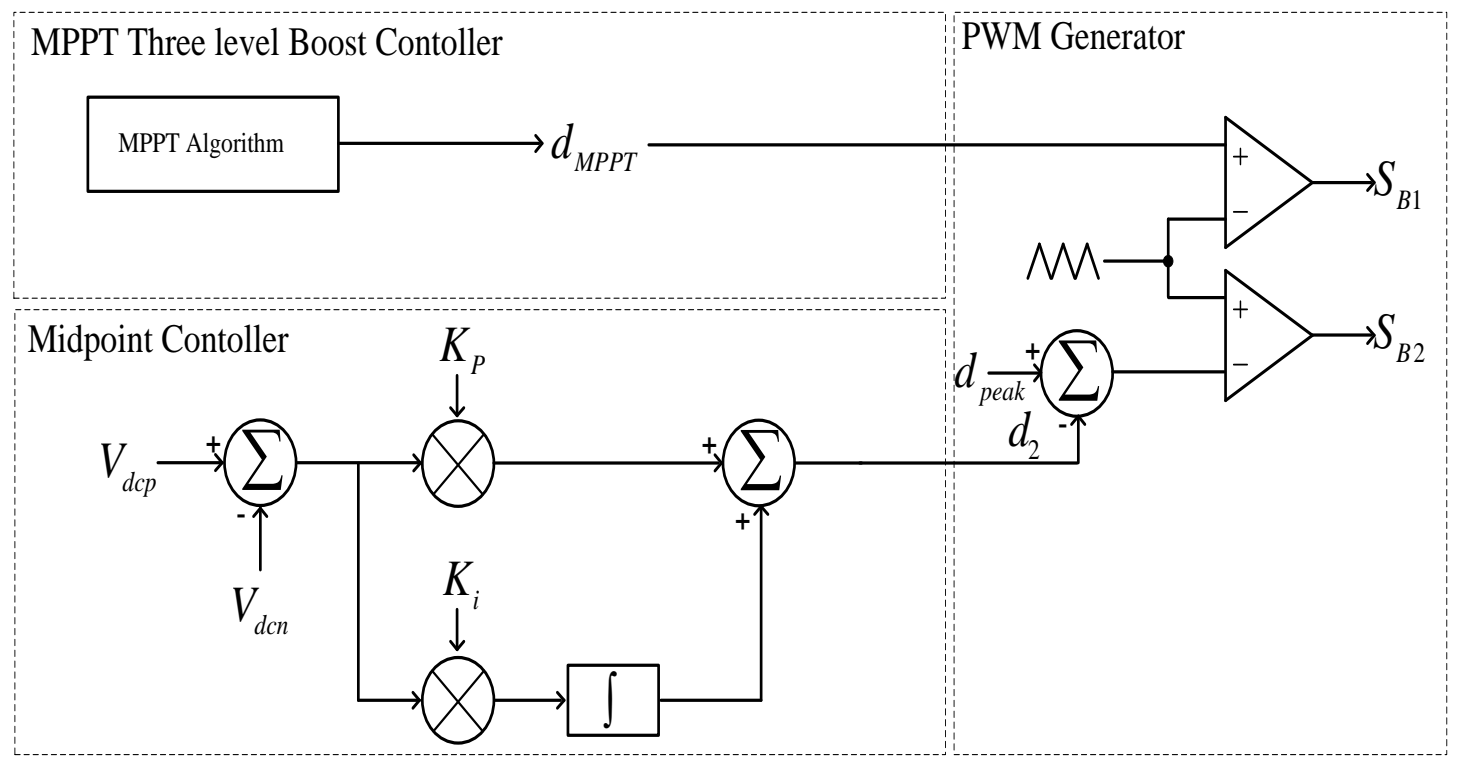

Figure 6. DC Link Voltage Balancing Controller for MPPT

Figure 6 shows a boost MPPT Controller proposed in this paper. When the DC link voltage is constantly maintained by the three level boost controller of Figure 3 and MPPT algorithm starts, it changes to MPPT three levels Boost controller of Figure 7. The $d_{1}$ outputted from the conventional controller is inputted as the default value of $d_{M P P T}$ of the converted controller. Through MPPT algorithm, $d_{M P P T}$ is changed and the conventional midpoint controller is to be maintained as it is.

\subsection{Three-Phase T-Type PV Inverter}

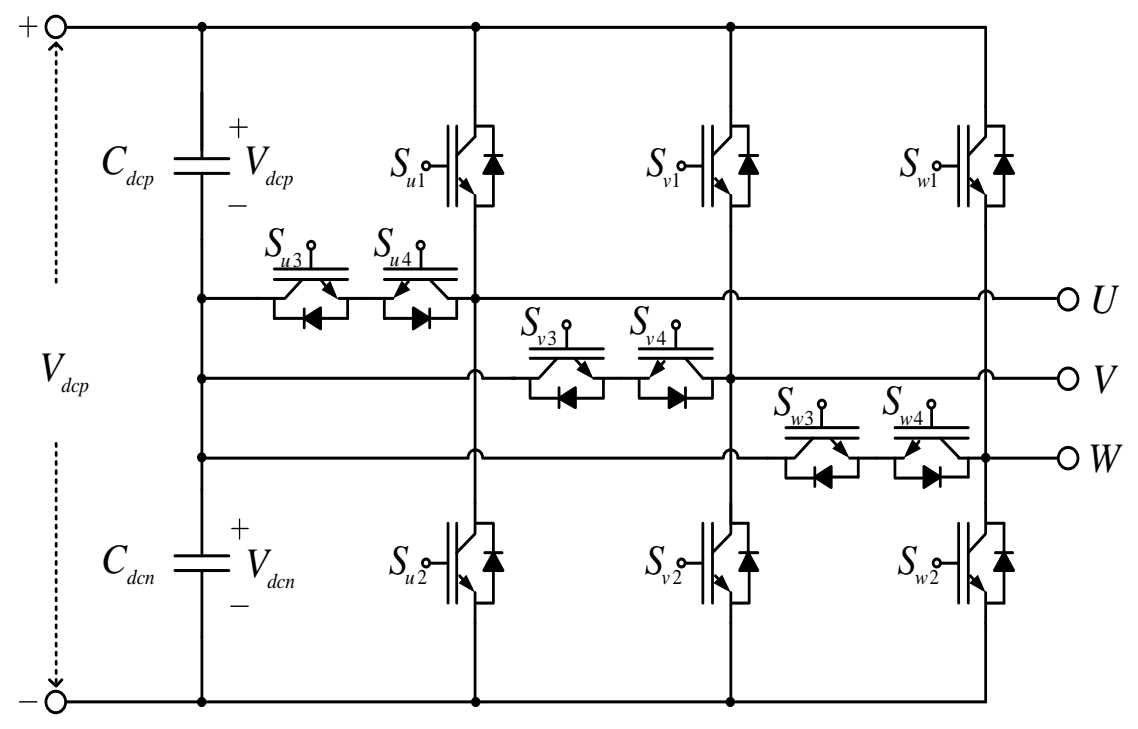

Figure 7. Circuit Diagram of a Three-phase T-Type PV Inverter 
T-Type inverter has the structure as Figure 7. Compared to the conventional two-level inverter, the power switch is to be increased by 6 pieces, but compared to the generally used diode clamp inverter; it is the structure to reduce 6 diodes [9].

Table 1 Switching States

\begin{tabular}{cccccc}
\hline State & $V_{\text {out }}$ & $S_{m 1}$ & $S_{m 2}$ & $S_{m 3}$ & $S_{m 4}$ \\
\hline \hline $\mathrm{P}$ & $+V_{d c p}$ & On & Off & On & Off \\
0 & 0 & Off & Off & On & On \\
$\mathrm{N}$ & $-V_{d c n}$ & Off & On & Off & On \\
\hline
\end{tabular}

Table 1 shows the output of each phase in accordance with a switching state The U, V, W phase of each output. $S_{p n}$ is each output of $\mathrm{U}, \mathrm{V}, \mathrm{W}$ phases. Here, $\mathrm{p}$ is each phase, and $\mathrm{n}$ is the number of the switch elements. When $S_{m 1}$ turns on, $V_{d c p}$ is outputted. When the bidirectional switch $S_{m 3}$ and $S_{m 4}$ turns on, 0 is outputted. When $S_{m 2}$ turns on, $-V_{d c n}$ is outputted. When the midpoint voltage is outputted from this system, the conduction is made through the bidirectional switch $S_{m 4}$ and $S_{m 4}$, but when using the upper and lower switches, only the switch $S_{m 1}$ and $S_{m 2}$ are conducted. So, it has the advantage to reduce the numbers of elements. It means, in all of the switching state, the conduction element has can reduce the conduction loss than diode clamped inverter with two conduction elements, and considering a three-level inverter switching losses are the same, the high efficiency can be structurally obtained [10].

\subsection{PLL (Phase Locked Loop)}

It is important that Grid-interactive photovoltaic inverters should be controlled and outputted by the phase and conduction of the grid voltage. To do this, the grid-connected photovoltaic inverter essentially requires PLL (Phase Locked Loop). When the phase difference between the grid and the inverter occurs, the system becomes unstable and the power quality degrades and then the reliability is hard to obtain.

\subsubsection{PLL Method of the Synchronization Coordinate System}

When power element three-phase voltage is in equilibrium and has each frequency $\omega$, and then, based on the phase voltage, the following equations can be obtained [11].

$$
\begin{gathered}
e_{a}=E \sin \omega t \\
e_{b}=E \sin \left(\omega t-\frac{2 \pi}{3}\right) \\
e_{c}=E \sin \left(\omega t+\frac{2 \pi}{3}\right)
\end{gathered}
$$

Also, the equation (1) is expressed in the d-q stationary coordinate system as the following equation.

$$
\begin{gathered}
e_{d}^{s}=E \cos \omega t \\
e_{q}^{s}=-E \sin \omega t
\end{gathered}
$$


Furthermore, the equation (2) is expressed in the d-q synchronous coordinate system as the following equation.

$$
\begin{aligned}
& e_{q}^{e}=E \\
& e_{d}^{e}=0
\end{aligned}
$$

From equation (2), the phase angle of the controller can be calculated by the following equation.

$$
\theta=\tan ^{-1}\left(\frac{-e_{q}^{s}}{e_{d}^{s}}\right)
$$

The synchronization coordinate q-axis power voltage calculated by the controller will be ' 0 ', when the control phase $\operatorname{angle}(\theta)$ is matching with the actual phase angle $\left(\theta^{*}\right)$, and in case that the control phase angle $(\theta)$ is ahead of the actual phase angle $\left(\theta^{*}\right)$, it will have value, and in case that the control phase angle $(\theta)$ is behind the actual phase angle $\left(\theta^{*}\right)$, it will have + value. Controlling by using PI controller to make the d-axis power supply voltage ' 0 ' in the synchronous coordinate system shown in Figure 4, it is possible to match the actual phase angle and the control phase angle.

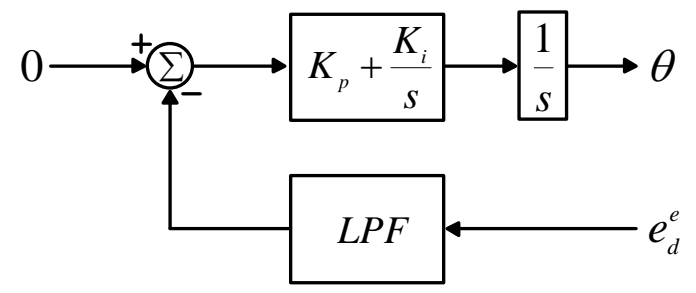

Figure 8 Structure of Phase Angle Controller

\subsubsection{PPL Method by Using the Extraction of the Normal Sequence}

PLL method using the conventional synchronous coordinate system is simple in principle and its implementation. However, if harmonic is mixed in power supply voltage, each extracted information shows the harmonic ripple. In order to remove the impact of power supply voltage un-equilibrium from the controller for the phase angle extraction, by obtaining the normal sequence voltage - that is, three phase equilibrium voltage - and use it as the input of the phase angle control extraction. Converting this obtained normal sequence voltage into the synchronous coordinate system, the inverse sequence voltage -which induces the ripple voltage corresponding to 2 times of the power supply frequencies if the existing unbalanced power voltage converts into the synchronous coordinate system disappears at the existing unbalanced power [11].

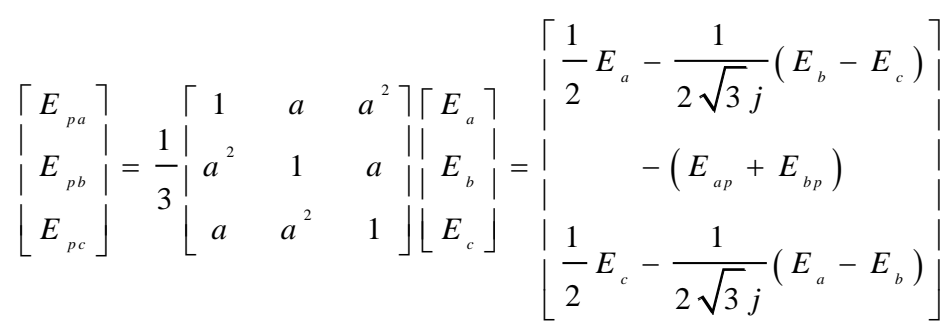




$$
\text { Where, } a=\exp \left(j \frac{2 \pi}{3}\right)
$$

\section{Experimental Results and Discussion}

In this paper, a $10 \mathrm{KW}$ class three phase grid connected photovoltaic inverter was designed and used. In order to control Boost Converter, DC to AC Inverter, MPPT (Maximum Power Point Tracking), PLL (Phase Locked Loop) and all the photovoltaic generation systems, the digital main controller is based on digital signal processor (K60FX512VLQ15) which is running at $150 \mathrm{MHz}$. The output voltage of the photovoltaic inverter is $380 \mathrm{~V} a c / 60 \mathrm{~Hz}$ and the rated current of the photovoltaic inverter was set as 15Aac. For inputting of photovoltaic inverter, instead of solar cell, REGARTRON CO's TopCon, and Quadro, and the simulation program, SAS Control were used. In addition, this paper showed the excellence of operating in conjunction with the actual grid. Table 2 shows the specifications of the controller.

Table 2. Controller Specifications

\begin{tabular}{|c|c|c|}
\hline \multicolumn{2}{|c|}{ specification } & value \\
\hline \multirow{2}{*}{ Processor } & DSP & K60FX512VLQ15 \\
\hline & System Clock & $150 \mathrm{MHz}$ \\
\hline \multirow{2}{*}{ A/D Converter } & Resolution & 16bit \\
\hline & Sample Frequency & $15 \mathrm{kHz}$ \\
\hline \multirow{2}{*}{ PWM } & Frequency & $15 \mathrm{kHz}$ \\
\hline & Dead Time & $2 \mathrm{us}$ \\
\hline
\end{tabular}

\subsection{Three Level Boost Converter}

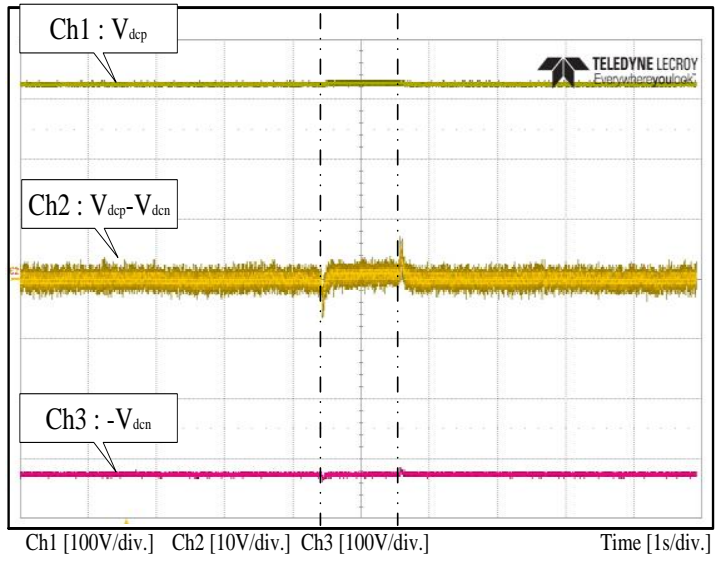

(a) Vdcp resistance variation: $250 \Omega$-> $166 \Omega$-> $250 \Omega$

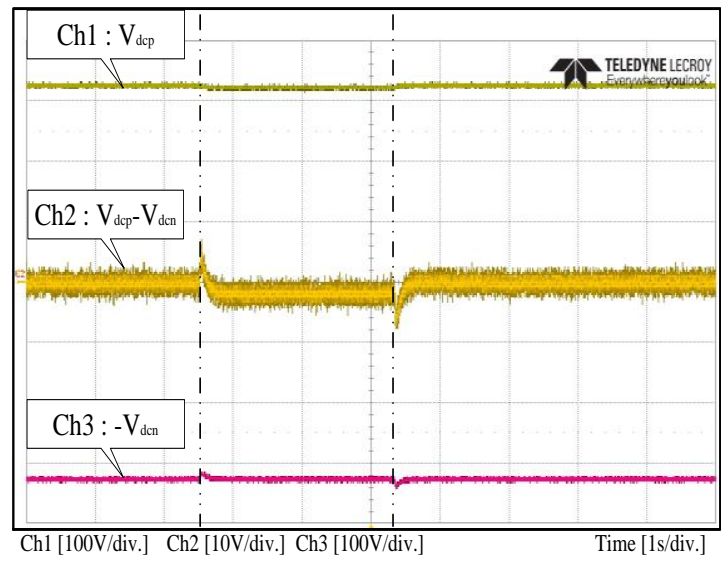

(b) Vdcp resistance variation: $250 \Omega$-> $166 \Omega$-> $250 \Omega$

Figure 9. Waveform of Resistance Load Variation

In Figure 9, by using the Boost Converter proposed in this paper, $320 \mathrm{~V}$ was boosted to $650 \mathrm{~V}$. The waveform of (a) is the waveform that fluctuated a resistance load from $250 \Omega$ to $166 \Omega$ at $V_{d c p}$ and after 1.5 seconds fluctuated it to $250 \Omega$ again and watched the result. 
And the waveform of (B) is the waveform that fluctuated a resistance load from $250 \Omega$ to $166 \Omega$ at $V_{d c n}$ and after around 3 seconds fluctuated it to $250 \Omega$ again and watched the output voltage. All of these two waveforms showed that midpoints were shown swaying at the initial stages of fluctuations.

However, within about $100 \mathrm{~ms}$, it was observed that they returned to the original voltages. At this time, the swaying voltage width has been stabilized within about $5 \mathrm{~V}$.

\subsection{MPPT (Maximum Power Point Tracking)}

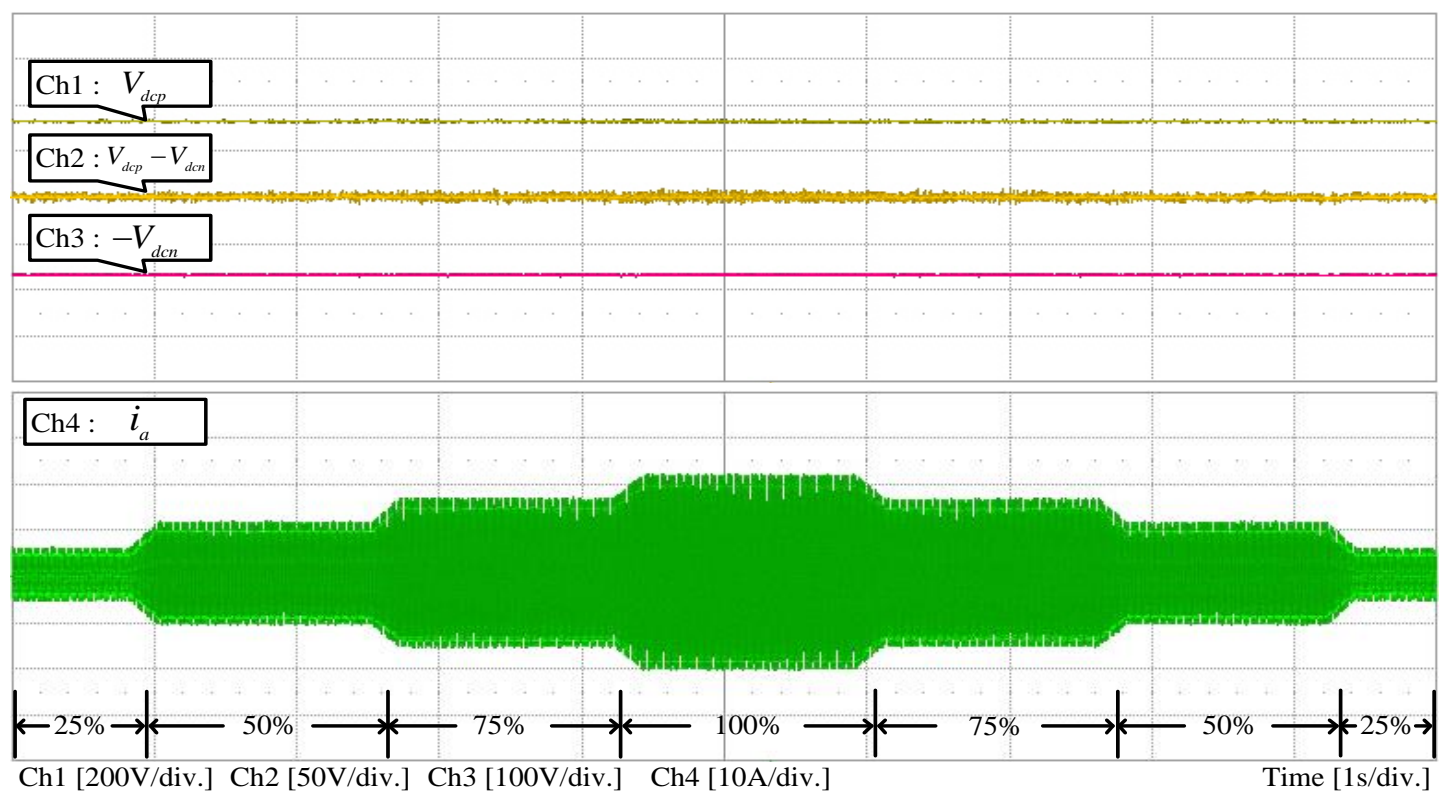

\section{Figure 10. Waveform of Solar Irradiance Fluctuation}

Figure 10 shows the DC link voltage and the output current of the photovoltaic inverter corresponding to the fluctuations of solar irradiance in order to show the excellence of MPPT (Maximum Power Point Tracking) proposed in this paper. It fluctuates for 0.5 second at $2.5 \mathrm{KW}$ and maintained for 1.5 seconds. It was observed that the un-equilibrium of DC link voltage was not created but maintained despite of the fluctuation of $25 \%$ solar irradiance, and also was confirmed that the output current of the inverter followed the maximum power stably.

Table 3. Efficiency of Maximum Power Point Tracking

\begin{tabular}{cc}
\hline Solar Irradiance & MPPT Efficiency \\
\hline \hline $100 \%$ & $99.95 \%$ \\
$75 \%$ & $99.94 \%$ \\
$50 \%$ & $99.94 \%$ \\
$25 \%$ & $99.93 \%$ \\
\hline
\end{tabular}


Table 3 presents the efficacy of MPPT( Maximum Power Point Tracking) corresponding to the fluctuation of solar irradiance. It was confirmed that more than $99.99 \%$ efficacy was generated and the proposed MPPT algorithm was great.

\subsection{Three-Phase Three-Level T-Type Inverter}

Figure 11 describes the voltage output of a 3-phase 3-level T-Type inverter. The output voltage of the inverter was $380 V_{R M S} / 60 \mathrm{~Hz}$, and DC link voltage was set as $650 V_{D C}$ for the experiment.

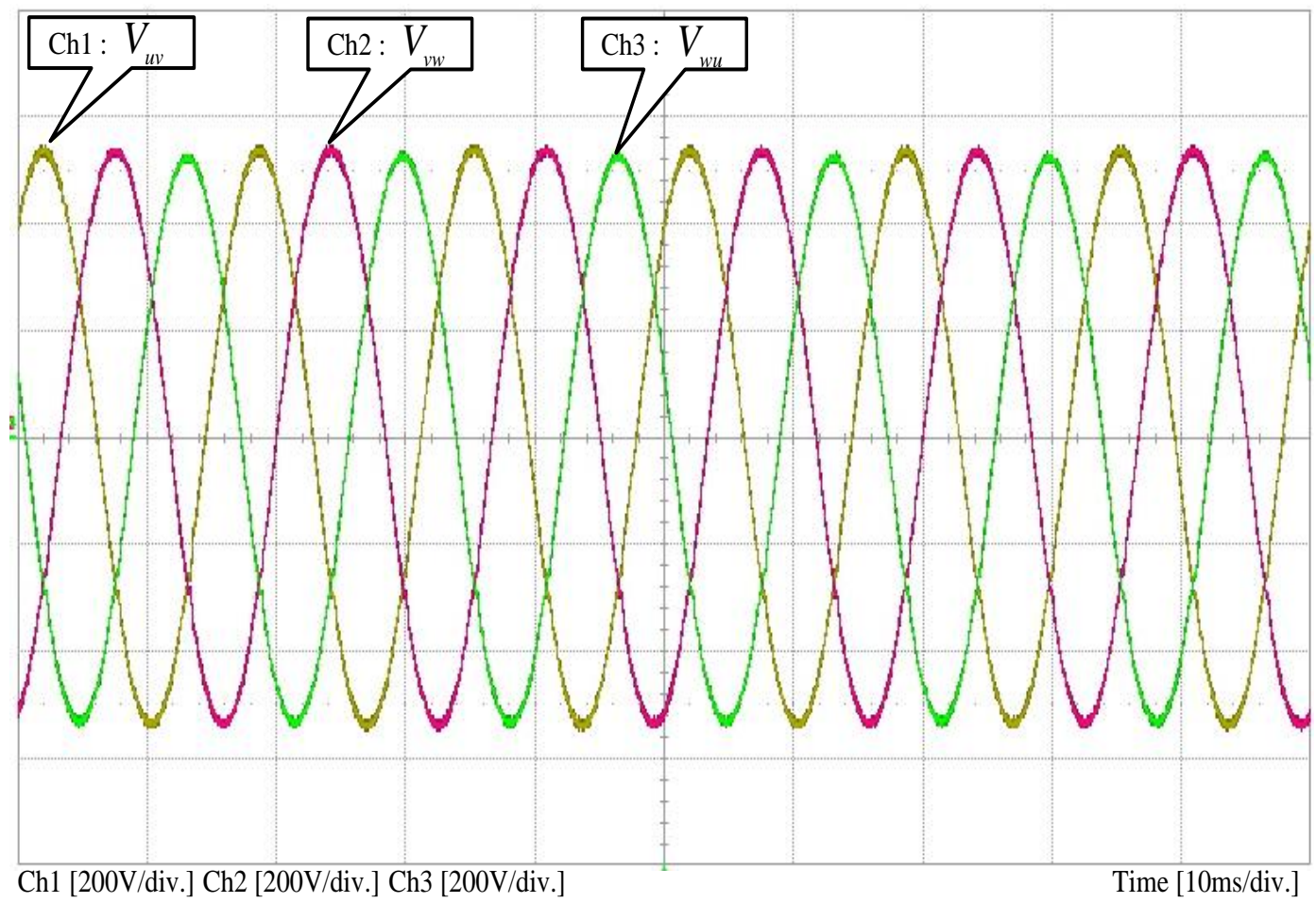

Figure 11. Waveform of Three-Phase T-Type PV Inverter

As seen in Figure 11, it was confirmed that the clean AC voltage was outputted.

Table 4. Efficiency of 3-phase 3-level T-Type Inverter

\begin{tabular}{cccc}
\hline Solar Irradiance & Input Power(kW) & Output Power & Efficiency (\%) \\
\hline \hline $100 \%$ & $9.9989 \mathrm{~kW}$ & $9.6792 \mathrm{~kW}$ & 96.8 \\
$75 \%$ & $7.4989 \mathrm{~kW}$ & $7.2515 \mathrm{~kW}$ & 96.7 \\
$50 \%$ & $4.9878 \mathrm{~kW}$ & $4.8088 \mathrm{~kW}$ & 96.4 \\
$25 \%$ & $2.4997 \mathrm{~kW}$ & $2.4025 \mathrm{~kW}$ & 96.1 \\
\hline
\end{tabular}

Table 4 shows the efficacy of a 3-level 3-phase T-type inverter. If more than $25 \%$ of solar radiation, the superior efficacy of more than $96 \%$ was confirmed. 


\section{Conclusion}

Compared to the conventional 2-level inverter, 3-level inverter has the disadvantages that require the control techniques on midpoint and the increase of number of power switches. However, it has the advantages such as the high efficacy of the inverter, low harmonic content, less stress on the power switch. This paper proposed the 3-level 3-phase T-type structure of the high efficient grid connected three phase photovoltaic inverter. Also, the 3level 3-phase T-type structure of the inverter control algorithm which controls the midpoint voltage was offered and its superiority was proved by experiment.

For the 3-level inverter, as the midpoint voltage may affect the output current of the inverter and also adversely impact the loads connected to the power grid, the difference between $\left(V_{d c p}\right)$ and $\left(V_{d c n}\right)$ should be maintained as $0 \mathrm{~V}$. To achieve this, it was verified the boost controller proposed in this paper maintained the difference of $\left(V_{d c p}\right)$ and $\left(V_{d c n}\right)$ as $0 \mathrm{~V}$.

The grid connected photovoltaic inverter needs to always generate the maximum power from the solar cell of the non-linear current characteristics. This paper verified that the efficacy of MPPT could be maintained more than $99.99 \%$ by the proposed MPPT algorithm which controlled the duty cycle of the boost converter, and confirmed the excellent MMPT performance was maintained despite of the fluctuation of solar irradiances by experiment.

\section{References}

[1] J. P. Lyons and V. Vlatkovic, "Power Electronics and Alternative Energy Generation", Proceedings of PESC 04, Germany, (2004) June, pp.16-21.

[2] A. Kaura and V. Blasko, "Operation of Phase Loop System Under Distorted Utility Conditions", IEEE Trans. Industry Applications, vol. 33, no.1, (1997), pp. 58-63.

[3] D. Floricau, E. Floricau and G. Gateau, "Three-level SNPC Commutation Cell: Features and Control”, IEEE International Symposium, Ind. Electron., (2008) June/July, pp. 44-49.

[4] K. Yamanaka, A. Hava, H. Kirino and Y. Tanaka et.al., "A Novel Neutral Point Potential Stabilization Technique Using the Information of Output Current Polarities and Voltage Vector", IEEE Trans. Industry Applications, vol. 38, no. 6, (2002) November, pp.1572-1580.

[5] K. Haddad, "Three Level DC-DC Converters as Efficient Interface in Two Stage PV Power System", IEEE Energy Tech , (2012) May, pp.1-6.

[6] J. M. Kwon and B. H. Kwon, "Three-Phase Photovoltaic System With Three-Level Boosting MPPT Control", IEEE Trans. on power electronics, vol. 23 , no. 5, (2008), pp. 2319-2327.

[7] S. H. Kim, H. N. Cha, H. G. Kim and B. C. Choi, "An Improved Non-Isolated 3-Level High Step-Up Boost Converter", The Transactions of the Korean Institute of Power Electronics, vol. 18, no. 4, August (2013), pp. 342-348.

[8] M. T. Zhang, Y. Jiang, F. C. Lee and M. M. Jovanovic, "Single-phase three-level boost power factor correction converter", Proceedings of APEC'95, vol. 1, (1995) March, pp. 434-439.

[9] U. M. Choi, H. H. Lee and K. B. Lee, "Simple Neutral-Point Voltage Control for Three-Level Inverters Using a Discontinuous Pulse Width Modulation”, IEEE Trans. Energy Conversion, vol. 28, no. 2, (2013) July, pp. 434-443.

[10] H. Shin, J. I. Ha, H. Seo and Y. J. Park, "Loss Analysis of T-type 3-level Inverter", Power Electronics Annual conference, (2012) July, pp. 54-55, Seoul, Korea.

[11] J. K. Ji, H. Kim, S. K. Sul and K. H. Kim, "PLL Strategy Having Frequency Limiter and Anti-windup Suitable to UPS”, Power Electronics Annual conference, (2004) July, pp. 778-782. 


\section{Authors}

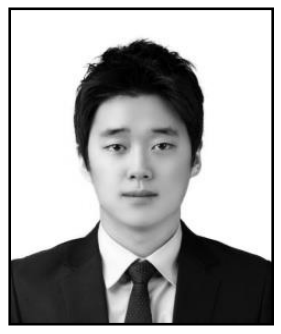

Jinsoo Kim, he received his B.A. degree in Semiconductor Engineering from Cheongju University, Korea, in 2013. He is currently working toward the M.S. degree in Electronic Engineering from Cheongju University, Korea. His research interests are converters for renewable energy and DSP control system

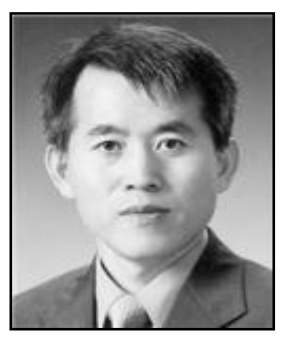

Oh Yang, he received his B.A., M.S., Ph.D. degree in Electrical Engineering from Han Yang University, Korea, in 1983, 1985, and 1997 respectively. From 1985 to 1997, he was research engineer at LGIS R\&D Lab. in the Department of Industrial Controller, An Yang, Korea. Since 1997, he has been with the Department of Electrical Engineering, Cheongju University, Korea. He was a visiting professor of A\&M University, Texas, USA, in 2006. He is currently a professor of the Semiconductor Engineering, Cheongju University, Korea. His research interests are converters for renewable energy, motor drives, power factor correction, and communication system for industrial controller. 
International Journal of Control and Automation Vol.7, No.10 (2014) 